of re-instating the International Congress to which we all look forward in the near future.

We heartily congratulate Professor Manolesco and his colleagues on their successful initiation.

\title{
"The Pre-School" Eye Clinic
}

The "News Letter" for October, 1926, issued by the National Committee of Blindness, New York, has just reached us, together with several pamphlets dealing with the hygiene of the eye and methods of sight saving classes from the same source; some of which we hope to notice in future numbers.

The report on the pre-school eye clinic, which has been in operation for rather more than a year, is very instructive and shows how much can be done to conserve vision in the very young, thereby increasing their potential value to the State.

The report shows that 225 visits were paid by 93 children of whom 22 were found to be normal with full vision; 5 children had a visual acuity of $20 / 30$, with normal eyes; and 3 had a worse acuity than this with normal eyes; 8 were found to be normal, but the vision is not noted; 15 children were too young to be tested, but had no ocular troubles ; 4 cases were referred to hospital for "serious difficulties"; 9 children had conjunctivitis, the nature of which is not stated, but we gather that trachoma did not play any part, and that the eyes were otherwise normal; 13 had strabismus, of whom one was myopic and one had blepharitis. There were two cases each of chalazion and epiphora; and one case each of cataract and choroido-retinitis. The children were mainly drawn from the neighbourhood of the clinic, but some came from farther afield. We presume that as the existence of the clinic becomes more extensively known, more cases will be sent to it from a distance. The staff consists of an ophthalmologist, a clinic manager, and a clinic assistant.

Notes of three cases of strabismus in which the defective eye improved markedly under treatment are detailed, and the report ends with the intimation that it has been decided to continue its good work for another year.

We have always felt that the establishment of some centre or centres in our large cities and towns which will cater for the eyes of those children who are below the school age and who have no obvious need to attend the eye departments of hospitals was a state of affairs much to be desired; we congratulate the National Committee on the success of the venture and express the hope that the clinic may become a permanent institution. 